\title{
Infection of Anopheles aquasalis from symptomatic and asymptomatic Plasmodium vivax infections in Manaus, western Brazilian Amazon
}

Keillen M. Martins-Campos ${ }^{1,2}$, Andrea Kuehn ${ }^{2,3}$, Anne Almeida ${ }^{1,2}$, Ana Paula M. Duarte ${ }^{1,2}$, Vanderson S. Sampaio ${ }^{4}$, Íria C. Rodriguez², Sara G. M. da Silva², Claudia María Ríos-Velásquez ${ }^{5}$, José Bento Pereira Lima ${ }^{6}$, Paulo Filemon Paolucci Pimenta ${ }^{2,7}$, Quique Bassat ${ }^{3}$, Ivo Müller ${ }^{3,8}$, Marcus Lacerda ${ }^{2,5}$, Wuelton M. Monteiro ${ }^{1,2}$ and Maria das Graças V. Barbosa Guerra ${ }^{1,2^{*}}$

\begin{abstract}
Background: Asymptomatic individuals are one of the major challenges for malaria elimination programs in endemic areas. In the absence of clinical symptoms and with a lower parasite density they constitute silent reservoirs considered important for maintaining transmission of human malaria. Studies from Brazil have shown that infected individuals may carry these parasites for long periods.

Results: Patients were selected from three periurban endemic areas of the city of Manaus, in the western Brazilian Amazon. Symptomatic and asymptomatic patients with positive thick blood smear and quantitative real-time PCR (qPCR) positive for Plasmodium vivax were invited to participate in the study. A standardised pvs 25 gene amplification by GPCR was used for $P$. vivax gametocytes detection. Anopheles aquasalis were fed using membrane feeding assays (MFA) containing blood from malaria patients. Parasitemia of 42 symptomatic and 25 asymptomatic individuals was determined by microscopic examination of blood smears and qPCR. Parasitemia density and gametocyte density were assessed as determinants of infection rates and oocysts densities. A strong correlation between gametocyte densities (microscopy and molecular techniques) and mosquito infectivity $(P<0.001)$ and oocysts median numbers $(P<0.05)$ was found in both groups. The ability to infect mosquitoes was higher in the symptomatic group (41\%), but infectivity in the asymptomatic group was also seen (1.42\%).
\end{abstract}

Conclusions: Although their infectivity to mosquitoes is relatively low, given the high prevalence of $P$. vivax asymptomatic carriers they are likely to play and important role in malaria transmission in the city of Manaus. The role of asymptomatic infections therefore needs to be considered in future malaria elimination programs in Brazil.

Keywords: Malaria, Gametocytes, Vector, Elimination, Membrane feeding assay

\footnotetext{
* Correspondence: mgvale@uea.edu.br

'Programa de Pós Graduação em Medicina Tropical, Escola Superior de

Ciências da Saúde, Universidade do Estado do Amazonas, Manaus, Brazil

${ }^{2}$ Departamento de Ensino e Pesquisa, Fundação de Medicina Tropical Dr.

Heitor Vieira Dourado, Manaus, Brazil

Full list of author information is available at the end of the article
} 


\section{Background}

Despite large reductions in burden in the least two decades [1], malaria remains one of the most important public health problems worldwide. Overall, it is estimated that 3.2 billion people in 97 countries and territories are at risk of being infected with Plasmodium species and developing the disease [1]. According to the World Health Organization (WHO), 214 million cases of malaria and 438,000 deaths were recorded in 2015 [1]. In Brazil, from January to November 2016, 114,287 malaria cases were recorded [2]. In the same period, the Amazonas state and Manaus reported 44,068 [3] and 9,058 [4] malaria cases, respectively.

The naturally acquired immunity against sexual forms of $P$. vivax in endemic regions remains unclear, as well as its interference with mosquitoes infectivity or "transmission-blocking effect" [5-7]. Transmission-blocking by antibodies against Plasmodium sexual forms has been increasingly becoming an important anti-malaria candidate strategy $[8,9]$. Although gametocytemia has a key role in malaria transmission, specific factors associated with the presence, spatial and temporal patterns, and infectivity of these sexual forms to mosquitoes are not well understood. Molecular markers of gametocyte stages include $p f s 25 / p v s 25$, which have been used successfully to detect gametocytes [10-13].

The potential transmission of the malaria parasite can be measured by Anopheles mosquitoes infection by gametocytes followed by detection of oocysts and sporozoites [14, 15]. Experimentally, mosquitoes can obtain a blood meal through a membrane $[15,16]$ or by biting infected individuals [17]. There are large discrepancies between the reported numbers of gametocytes and their infectivity. High densities do not necessarily result in infection whereas low densities can lead to infectivity [18].

Parasite infectivity is affected by vector competence and host's immunity and genes [19]. The infectivity of Plasmodium gametocytes to Anopheles mosquitoes has been shown to be modulated by several molecules such as the antibody-like protein $p f s 27 / 25$ found in the sera of people exposed to malaria [20]. In addition to the relationship between mosquito infectivity and transmission-blocking immunity [21], complement system activation [22] and leukocytes [23] that phagocytose gametes inside the mosquito midgut shortly after the mosquito takes a blood meal [19, 24], a number of studies suggest a role for immune status in the transmission reduction of $P$. falciparum malaria [24, 25].

The presence of specific anti-pfs $48 / 45$ and anti-pfs 230 monoclonal antibodies in the mosquito blood meal also results in transmission reduction [26]. The combination of all these specific hosts and vector factors, i.e. the vector immune system, the vector capacity, the relation of the mosquito infectivity and transmission block immunity, determine the variability and ability of gametocytemic individuals to infected mosquitoes.

Active detection of all parasite carriers and prompt treatment are critical to interrupt malaria transmission [27]. However, asymptomatic cases of malaria constitute a major challenge for elimination programs, especially regarding quantitation of parasitemia [28]. The use of a cut-off parasite density limit for the classification of asymptomatic infections and molecular tools have been suggested [29].

A cross-sectional study carried out in 2012 in the communities of Brasileirinho, Puraquequara, and Ipiranga and also analysed in the present study, showed that the prevalence of asymptomatic infection was 3.67\% (74/2012), which corresponded to $85.06 \%(74 / 87)$ of the total $P$. vivax carriers (unpublished data). A 2002 study of native Amazonian populations showed that the prevalence of asymptomatic infections was $14.6,21.7$, and $6.4 \%$ in the three surveys at the same time, respectively, with a higher prevalence of asymptomatic infections in older age groups (odds ratio of 6.67 for people older than 40 years) [30]. Thus, the chances of presenting an asymptomatic infection increased significantly with age (Chi-square test for trend, $\left.\chi^{2}=10.53, P=0.001\right)$.

The main challenge of asymptomatic malaria is the identification of the individuals with low parasitemia which may constitute a parasite reservoir hindering malaria eradication efforts. Prevalence of asymptomatic cases of malaria varies considerably according to population age, previous exposure to malaria and probably also due to parasite and host immune factors [27, 31-33]. The natural protective immunity to $P$. vivax and $P$. falciparum infection in very low transmission is not understood in the context of current thinking about how natural immunity is acquired [34]. In the absence of evidence for the infectivity of these infections to mosquitoes, their role in and potential contribution to local malaria transmission remains unclear. This study thus aimed at understanding the role and impact of symptomatic and asymptomatic carriers on $P$. vivax transmission in the endemic region of Manaus in the western Brazilian Amazon.

\section{Methods}

\section{Study area and patient recruitment}

Here, we conducted a cross-sectional study. Symptomatic patients were recruited at the Fundação de Medicina Tropical Dr Heitor Vieira Dourado (FMTHVD) between April 2013 and February 2015. Asymptomatic participants were recruited in the localities of Brasileirinho, Puraquequara, and Ipiranga, located in the periurban area of Manaus, state of Amazonas, Brazil (Fig. 1). Samples were collected in these areas from June 2014 to May 2015. Each 


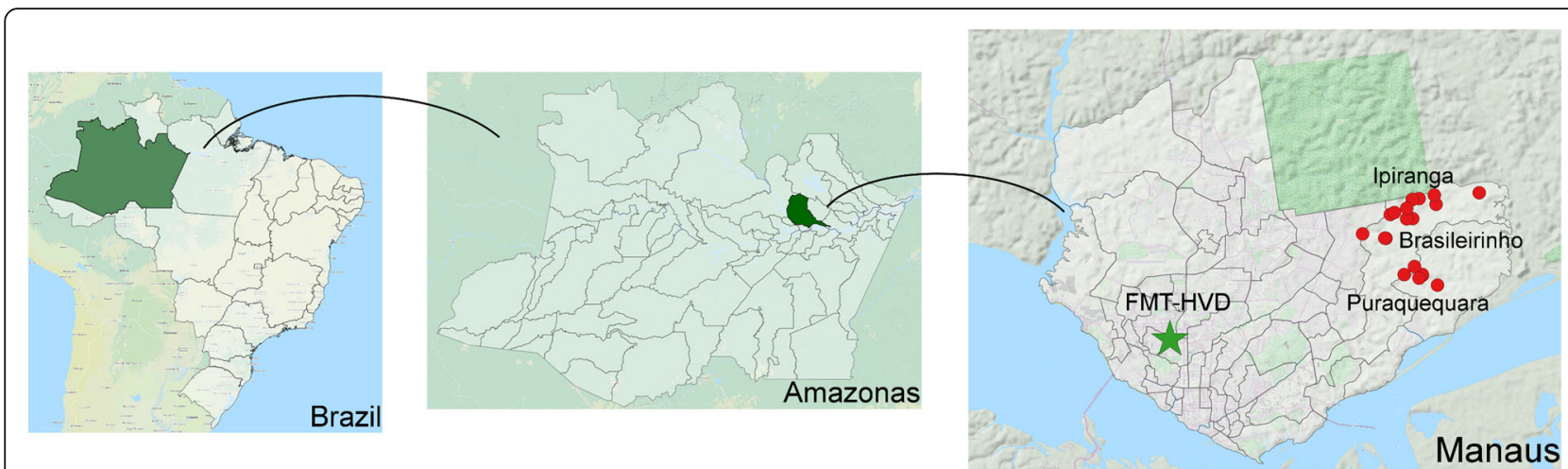

Fig. 1 Hotspots of three communities of asymptomatic (red circles) and symptomatic (green star) malaria infections in the study area examined here. Samples from symptomatic and asymptomatic individuals were collected in the city of Manaus; symptomatic patients were all from Fundação de Medicina Tropical Dr Heitor Vieira Dourado (FMTHVD), a reference centre in tropical and infectious diseases, and the asymptomatic cases came from three peri-urban communities of the city

locality has a full-time microscopy post, where the diagnosis of malaria is carried out. Daily, municipal health agents visit the residents through active and passive case detection. The clinical and parasitological characteristics of participants determined in this study are summarised in Table 1.

From symptomatic patients with positive thick blood smear, $2 \times 5 \mathrm{ml}$ blood samples were collected by venipuncture and stored at $37{ }^{\circ} \mathrm{C}$ until further processing. One heparinised sample was used to feed mosquitoes and the second (EDTA) tube was used for molecular procedures. Fifty $\mu$ l of EDTA whole blood were transferred to RNAprotect (Qiagen, Hilden, Germany) within $1 \mathrm{~h}$ after sample collection. No patient had been on anti-malarial therapy during enrollment to the study. Data regarding age, sex, occupation, place of

Table 1 Clinical aspects, infectivity mosquitoes and prevalence of asexual and sexual stages detected by microscopy and/or molecular biology tools in samples from symptomatic and asymptomatic malaria vivax patients

\begin{tabular}{|c|c|c|}
\hline & Symptomatic $(n=42)$ & Asymptomatic $(n=25)$ \\
\hline Male, $n(\%)$ & $31(74)$ & $14(56)$ \\
\hline \multicolumn{3}{|l|}{ Age group (\%) } \\
\hline$<25$ & 12 & 24 \\
\hline $25-34$ & 24 & 28 \\
\hline$>34$ & 64 & 48 \\
\hline Mean & 39 & 34.7 \\
\hline Malaria previous episodes (\%) & 88 & 84 \\
\hline Mean of malaria episodes & 4 & 9 \\
\hline \multicolumn{3}{|l|}{ Symptoms (\%) } \\
\hline Fever & 93 & 0 \\
\hline Headache & 31 & 12 \\
\hline Chills & 52 & 0 \\
\hline No. of dissected guts, mean \pm SD (range) & $27.6 \pm 13.3(11-85)$ & $28.5 \pm 13.1(7-60)$ \\
\hline Oocyst intensity, mean \pm SD (range) & $7.8 \pm 18.1(0-70)$ & $2.1 \pm 7.3(0-35)$ \\
\hline \multicolumn{3}{|l|}{ 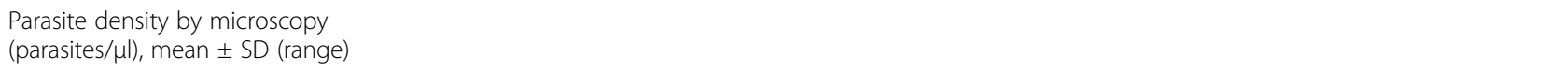 } \\
\hline Assexual forms, mean $\pm \mathrm{SD}$ (range) & $2454 \pm 3148(165-13,524)$ & $249 \pm 724(0-3128)$ \\
\hline Gametocytes, mean \pm SD (range) & $152 \pm 130(8-577)$ & $13 \pm 33(0-151)$ \\
\hline \multicolumn{3}{|l|}{ PCR parasite density (copies/ $\mu$ l) } \\
\hline $18 \mathrm{~S}$ rDNA, mean \pm SD (range) & $14,134 \pm 75,180(1446-478,640)$ & $2446 \pm 5495(0.7-20,627)$ \\
\hline Pvs25, mean \pm SD (range) & $8937 \pm 31,745(505-175,571)$ & $2711 \pm 3444(1-10,858)$ \\
\hline
\end{tabular}


residence, and history of malaria were collected in a questionnaire. Fever (axillary temperature $\geq 37.5{ }^{\circ} \mathrm{C}$ at admission or history of fever in the last $48 \mathrm{~h}$ ) and other signs and symptoms were assessed before blood collection. Tubes and questionnaires were individually barcoded in the laboratory before blood collection.

Asymptomatic patients were diagnosed using $300 \mu \mathrm{l}$ of whole blood collected with a fingerstick lancet and placed in a microtube containing anticoagulant (EDTA/ sodium fluoride), the final concentration was $1.8 \mathrm{mg} / \mathrm{ml}$. DNA was extracted from these samples using the FavorPrep $^{\text {TM }}$ 96-well Genomic DNA Kit (Favorgen, PingTung, Taiwan) and they were tested for the presence of Plasmodium spp. infections using a validated, genusspecific qPCR for the detection of Plasmodium spp. (Qmal assay) (Additional file 1: Table S1, Additional file 2: Table S2) [35]. In case of a positive result for individuals who accepted to take part in the study, samples of venous blood were collected as described above. Individuals were considered asymptomatic when they did not present symptoms of malaria, thirty days before and thirty days after the blood collection to detect $P$. vivax.

\section{Plasmodium vivax peripheral parasitemia and gametocyte counts by light microscopy}

Thick blood smears were Giemsa-stained and analysed by light microscopy for malaria parasite species and peripheral parasite counting by at least two independent trained microscopists. Inconsistencies were solved by a senior microscopist. The mean parasitemia was used. Parasite densities (parasites/ $\mu \mathrm{l}$ ) were calculated by counting the number of asexual and sexual parasites stages per 500 leukocytes.

\section{Assessment of $P$. vivax infectivity to mosquitoes}

Anopheles aquasalis mosquitoes were reared under standard laboratory conditions at $27{ }^{\circ} \mathrm{C}$ with $80 \%$ humidity on a $12 \mathrm{~h}$ light/dark cycle. Mosquitoes were provided with $10 \%$ sucrose solution ad libitum until one day before the infective blood meal, as described previously [36, 37].

Anopheles aquasalis were infected with $P$. vivax by feeding blood collected from patients diagnosed with malaria using an artificial membrane feeding system [37]. Blood samples were maintained at $37^{\circ} \mathrm{C}$ no later than one hour until membrane feeding assays. The second group was treated similarly but with inactivated-blood serum (IBS). The $P$. vivax infective blood samples were centrifuged for $1 \mathrm{~min}$ at $37^{\circ} \mathrm{C}$, and the serum was removed and heated for $1 \mathrm{~h}$ at $56^{\circ} \mathrm{C}$ in a water bath to inactivate the complement system. In both groups, the mosquitoes were 3 to 5 days old (100 per cage for each group) and allowed to feed for $2 \mathrm{~h}$ in the dark. Afterwards, engorged females were kept with $10 \%$ sucrose daily until they were dissected on day 7 after feeding. The midguts were dissected in a drop of mercurochrome in phosphate-buffered saline, and oocysts were counted by examination under $10 \times$ light microscopy at $100 \times$ magnification (Additional file 3: Table S3).

\section{Molecular detection of asexual and sexual of Plasmodium vivax}

EDTA blood was stored at $37^{\circ} \mathrm{C}$ until samples processing. For RNA extraction, $50 \mu \mathrm{l}$ of EDTA blood was transferred to $250 \mu \mathrm{l}$ of RNAprotect transferred about $30 \mathrm{~min}$ after sample collection. The samples were immediately stored at $-80{ }^{\circ} \mathrm{C}$. A volume of $200 \mu \mathrm{l}$ was stored for DNA isolation. The genomic DNA was extracted from the pelleted RBCs obtained from $200 \mu$ l blood using FavorPrep ${ }^{\mathrm{TM}}$ 96-well Genomic DNA kit (Favorgen) according to the manufacturer's instructions. RNA from whole blood stored in RNAprotect at $-80{ }^{\circ} \mathrm{C}$ was extracted using the RNeasy ${ }^{\circ}$ Plus 96 kit (Qiagen) as described [35].

Both the Qmal and species-specific qPCR assays target the $18 \mathrm{~S}$ rRNA gene, as previously described [35, 38]. Data were analyzed using standard curves of dilutions of the plasmids containing the target sequences (kindly provided by I. Felger, Swiss TPH, Basel). $\mathrm{C}_{\mathrm{q}}$ values (cycle threshold) of standard plasmids were used to determine the number of copies for the genes of interests for each sample. Analyses were performed by the software distributed by the manufacturer (Applied Biosystems' 7500 Fast System SDS Software, Waltham, Massachusetts, USA).

Plasmid dilutions were tested in quintuplicates. For the detection limit, three of the five dilutions had to be positive for $P$. vivax: 3 copies $/ \mu \mathrm{l}$, pvs 25 : $0.5 \mathrm{copy} / \mu \mathrm{l}$ [35]. The efficiency of the methodology tested in the laboratory LODs was for $P$. vivax: 1 copy/ $\mu$ lefficiency 92.18\%) and pvs25: 0.5 copy/ $\mu \mathrm{l}$ (efficiency 96.20\%) (Additional file 4: Table S4).

Detection of $P$. vivax gametocytes by RT-qPCR to detect pvs 25 transcripts of this gametocyte-specific gene was performed as previously described [35]. Plasmids served as positive controls and as standards for the quantification of DNA samples. Three dilutions used were: $10^{2}, 10^{4}$ and $10^{6}$ copies/ $\mu l$ of the plasmids containing the gene fragment to be amplified. Analyses were performed using the Applied Biosystems software 7500 Fast System SDS Software.

\section{Statistical analysis}

A person was defined as a transmitter if his/her blood sample had successfully infected at least one mosquito. A t-test was also used to compare the median percentage of mosquitoes infected by parasitemia group, and the MannWhitney $U$-test was used to compare the number of oocysts per infected midgut with parasitemia group. 
Relationships between the RT-qPCR quantification of gametocytes, gametocytemia, oocysts per infected midgut, and percentage of mosquitoes infected were compared using Pearson correlation analysis. Two-sided $P$-values $<0.05$ were considered statistically significant. To assess whether gametocytemia would correctly classify mosquito infection, non-parametric receiver operating characteristic (ROC) analysis was performed. The area under the ROC curve (AUROC) was also calculated including its confidence intervals to measure the discriminative ability of gametocytemia as a predictor of mosquito infection.

\section{Results}

\section{Study population}

Sixty-seven participants were included in the study, of these 42 were symptomatic and 25 asymptomatic. The mean age of symptomatic patients was 39 years, and $88 \%$ of participants reported to have had at least one previous case of malaria (median: 3 episodes, range 1$20)$. The main symptoms reported by patients were fever (93\%), chills (52\%) and headache (31\%). The mean parasitemia determined by light microscopy was 2454 parasites/ $\mu \mathrm{l}$ (range 165-13,524) for asexual stages and 152 parasites/ $\mu$ l (range 8-577) for gametocytes, with the proportion of $83 \%$ (35/42). By qPCR, 40/42 patients were positive (95\%) with an average 14,134 18S rRNA copies/ $\mu \mathrm{l}$ (range 1446-478,640) and 8937 pvs25 transcripts/ $\mu \mathrm{l}$ (range 505-175,571) (Table 1).

At first 35 volunteers were enrolled as asymptomatic cases but ten of them were excluded as they showed symptoms within 15 days after recruitment, totalling 25 individuals for statistical analysis. The mean age of asymptomatic patients was 34.5 years with $85 \%$ of participants reporting having had at least one case of the disease (median: 9 episodes, range 1-43). The three $(12 \%)$ asymptomatic individuals reported headaches. The mean parasite density as determined by light microscopy was 249 asexual stage parasites/ $\mu \mathrm{l}(0-3128)$ and 13 gametocytes/ $\mu \mathrm{l}(0-151)$. The average number of copies of 18S rRNA was 2446 (0.7-20,627), and 2711 (1-10,858) for the pvs 25 transcripts based on RT-qPCR analyses, in both cases $4 \mu \mathrm{l}$ of blood volume were used (Table 1 ).

\section{Parasitemia and gametocytes detection}

By optical microscopy, 83\% (35/42) of the symptomatic patients were positive for asexual and sexual stages of $P$. vivax. In asymptomatic patients only $40 \%$ (10/25) of analyzed samples were positive for $P$. vivax asexual stages and $24 \%(6 / 25)$ were positive for $P$. vivax gametocytes by light microscopy (Mann-Whitney U-test, $U_{(72)}=174$, $Z=5.61, P<0.0001$ and $U_{(72)}=152, Z=5.94, P<$ 0.0001 , Fig. $2 \mathrm{a}$ and $\mathrm{b}$, respectively). The symptomatic
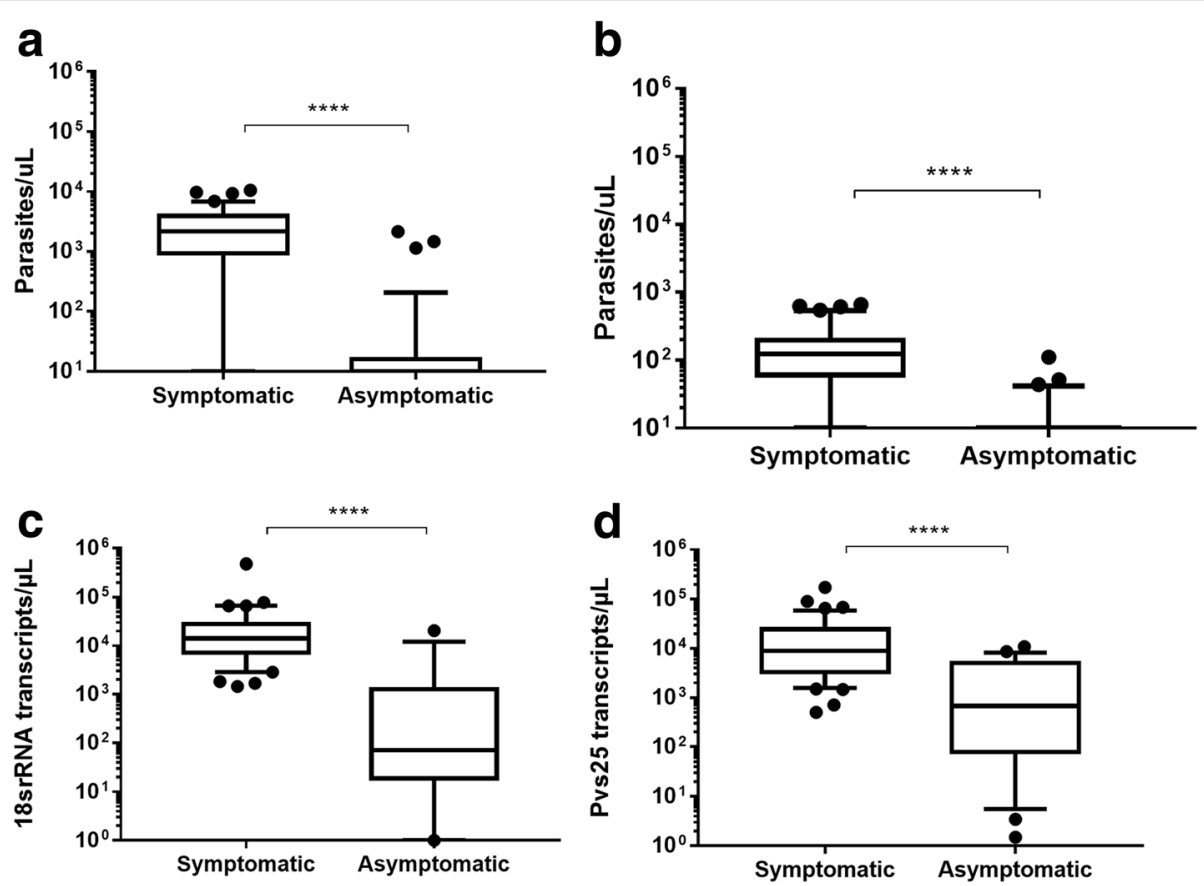

Fig. 2 Parasitemia distribution in the symptomatic and asymptomatic groups. Semilogarithmic plots of asexual forms (a) and gametocytes (b) as determined by microscopy and parasite density estimated by the number of copies of $18 \mathrm{~S}$ rRNA (c) and pvs 25 (d) are shown for symptomatic and asymptomatic blood samples. The symptomatic group showed the significantly higher density of both asexual forms (a) and gametocytes (b) $(P<0.0001)$ the parasite density was observed in the number of copies of $18 \mathrm{~S}$ rRNA (c) and pvs 25 transcripts (d). The means were compared using the Mann-Whitney test (*** $P<0.0001)$, and the error bars represent the standard error of the mean (SEM) 
group showed significantly higher densitiy of number of copies of $18 \mathrm{~S}$ rRNA and pvs 25 transcripts (Mann-Whitney U-test, $U_{(56)}=53, Z=5.16, P<0.0001$ and $U_{(64)}=$ 158, $Z=4.61, P<0.0001$, Fig. $2 c$ and d).

Gametocytes detected by either microscopy and RTqPCR showed $83 \%$ and $100 \%$ for symptomatic and $23 \%$ and $88 \%$ for asymptomatic infections, respectively.

A strong positive association for the gametocytedetection techniques used (optical microscopy and pvs25 transcripts measured by RTqPCR) was observed $\left(r_{(61)}^{2}=\right.$ $0.529, P=0.001$, Fig. 3 ) highlighting a complementary useful approach in malaria diagnosis.

\section{Infectivity of asymptomatic patients}

Asymptomatic patients had low parasitemias (Table 2), most of them submicroscopic, yet some were able to infect mosquitoes. Thirteen samples (50\%) had negative slides for $P$. vivax asexual forms, 18 (69\%) for gametocytes, and for two patients (8\%), microscopy data were not available. In the asymptomatic group, the average infection rate was $1.42 \%$, ranging from at least 0.91 to $24.24 \%$; the average oocyst number for each sample ranged from 1-35 oocysts.

Although the asymptomatic group with low submicroscopic parasitemia showed infectivity to mosquitoes, the two groups showed significant differences in infectivity and median oocysts by the (Mann-Whitney U-test, $U_{(72)}$ $=280, Z=4.66, P<0.0001$ and $U_{(66)}=267.5, Z=3.99$, $P<0.0001$, Fig. $4 \mathrm{a}$ and $\mathrm{b}$, respectively).

A strong correlation was observed between pvs25 transcripts and mosquito infection rate in the symptomatic and asymptomatic samples $\left(r_{(69)}^{2}=0.567, P<0.001\right.$, Fig. 5a) whereas the correlation was weaker between the median of oocysts and gametocytes in the same groups $\left(r_{(61)}^{2}=0.286\right.$, $P<0.05$, Fig. 5b).
Furthermore, ROC analysis revealed that the geometric mean of gametocytes from symptomatic and asymptomatic individuals detected by light microscopy could be considered an acceptable classifier for mosquito infection (AUROC: 0.8293, CI: 0.73-0.93) (Fig. 6). A cutoff of 58.78 gametocytes/ $\mu$ l correctly classified $81.94 \%$ of the mosquito infections (sensitivity of $82.35 \%$, specificity of $81.58 \%$ ).

There was no significant difference in the production of oocysts when MFAs were set up with infective samples consisting of whole blood (WB) or inactivated blood serum (IBS) (Mann-Whitney U-test, $U_{(40)}=219, Z=$ 2.019, $P=0.9748$, Fig. 7). Thus, inactivation of complement factors present in blood serum did not affect median oocysts as an indicator of infectivity.

\section{Discussion}

Asymptomatic infections often go unnoticed and consequently untreated, resulting in important sources of gametocytes for local vectors. These infections and their contribution transmission are poorly understood, and there are few if any intervention that directly deals with them.

In this study, submicroscopic gametocyte carriage was common in an endemic malaria area in Manaus. Although these patients exhibited low parasitemia, their blood was nevertheless able to infect Anopheline mosquitoes. All parasitemia (asexual and sexual forms) rates were highest in symptomatic patients. Asymptomatics are showing a higher proportion of mature gametocytes (pvs25 transcripts) were as effective as symptomatic in infecting mosquitoes (Fig. 5). A recent report from malaria-endemic regions in Colombia also showed the prevalence of $P$. vivax asymptomatic submicroscopic infections with mostly gametocytes as circulating parasites,

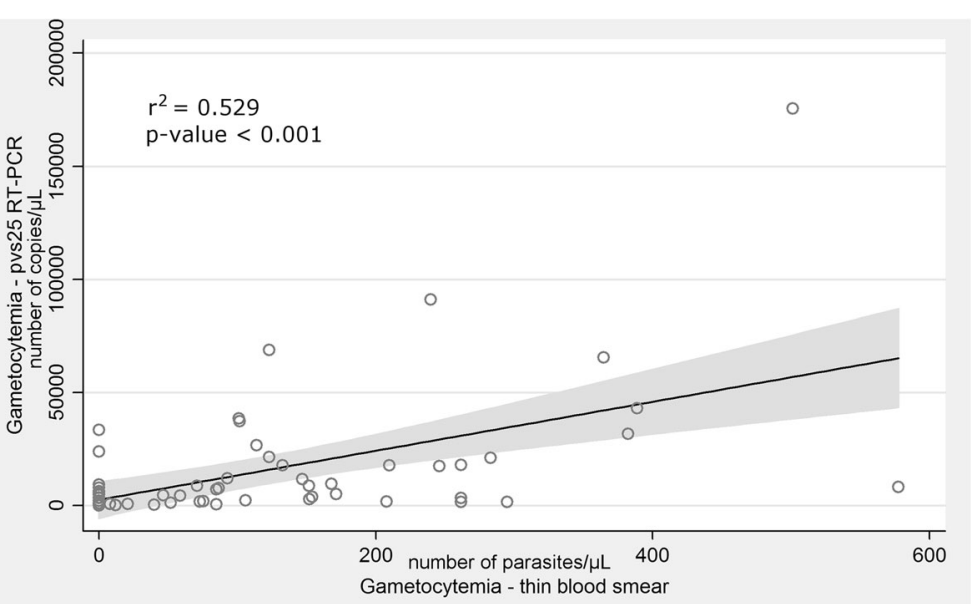

Fig. 3 Correlation between gametocytes measured by levels of pvs25 P. vivax transcripts and gametocytes visualised by microscopy. A strong positive association between gametocyte numbers detected by RT-qPCR and those visualised by microscopy in thin blood smears from symptomatic individuals. The values indicate the correlation coefficient $\left(r^{2}\right)(P$-value $<0.001)$ 
Table 2 Susceptibility of An. aquasalis mosquitoes to infection with P. vivax from Brazilian asymptomatic patients

\begin{tabular}{|c|c|c|c|c|c|c|c|}
\hline \multirow{2}{*}{$\begin{array}{l}\text { Patient } \\
\text { ID }\end{array}$} & \multicolumn{2}{|c|}{ Thin blood smear (parasites/ $\mu$ l) } & \multicolumn{2}{|c|}{ 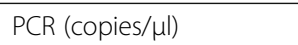 } & \multirow{2}{*}{$\begin{array}{l}\text { Infection } \\
\text { rate (\%) }\end{array}$} & \multirow{2}{*}{$\begin{array}{l}\text { Oocysts } \\
\text { median (IQR) }\end{array}$} & \multirow{2}{*}{$\begin{array}{l}\text { Symptom } \\
\text { free days }\end{array}$} \\
\hline & $\overline{A s x}$ & Gam & 18 srRNA & Pvs25 & & & \\
\hline 1 & 0 & 0 & 16 & nd & 24.24 & $25(16-34)$ & ns \\
\hline 2 & 21 & 0 & nd & 6192 & 10 & $30(-)$ & ns \\
\hline 3 & 0 & 0 & nd & 2072 & 12.5 & $35(31.5-38.5)$ & ns \\
\hline 4 & 88 & 52 & 29 & 1263 & 0 & 0 & 7 \\
\hline 5 & 0 & 0 & 51 & 1002 & 0 & 0 & ns \\
\hline 6 & nd & nd & 62 & 595 & 0 & 0 & ns \\
\hline 7 & nd & nd & nd & 10,858 & 5.71 & $1(1-1)$ & ns \\
\hline 8 & 201 & 12 & 19 & 82 & 0 & 0 & ns \\
\hline 9 & 3128 & 152 & 20,627 & 8686 & 14.89 & $12.25(9-20)$ & 10 \\
\hline 10 & 2034 & 59 & 11,246 & 4393 & 5.12 & $7(5.5-8.5)$ & 1 \\
\hline 11 & 77 & 0 & 97 & 240 & 0 & 0 & ns \\
\hline 12 & 94 & 0 & 694 & 5190 & 0 & 0 & 14 \\
\hline 13 & 0 & 0 & 186 & 252 & 0 & 0 & 30 \\
\hline 14 & 0 & 0 & 1 & 23 & 0 & 0 & 4 \\
\hline 15 & 0 & 0 & 1 & 147 & 1.69 & $1(-)$ & 1 \\
\hline 16 & 301 & 40 & 58 & 262 & 0 & 0 & ns \\
\hline 17 & 0 & 0 & 78 & 48 & 2.06 & $3.5(2.75-4.25)$ & ns \\
\hline 18 & 0 & 0 & nd & nd & 0.91 & $1(-)$ & ns \\
\hline 19 & 0 & 21 & nd & 757 & 0 & 0 & 5 \\
\hline 20 & 211 & 0 & nd & 8 & 0 & 0 & ns \\
\hline 21 & 0 & 0 & nd & 2 & 0 & 0 & 7 \\
\hline 22 & 65 & 0 & nd & 4 & 0 & 0 & ns \\
\hline 23 & 0 & 0 & 5005 & 4612 & 0 & 0 & ns \\
\hline 24 & 0 & 0 & 82,849 & 7855 & 0 & 0 & ns \\
\hline 25 & 0 & 0 & 2558 & 7817 & 0 & 0 & ns \\
\hline
\end{tabular}

Abbreviations: $n d$ not determined, $n s$ no symptoms, IQR interquartile range (25th and 75th percentile), SD standard deviation, (-) single positive mosquito
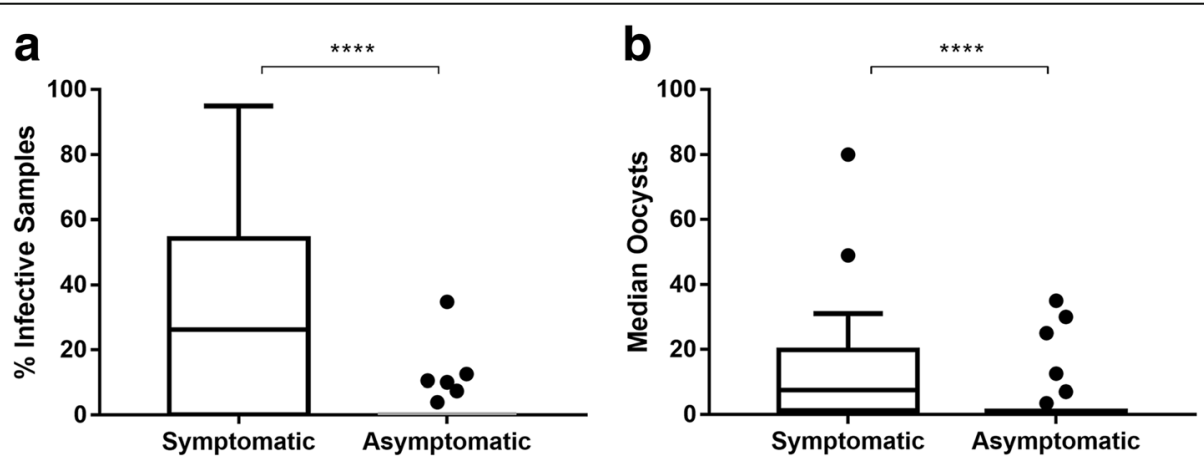

Fig. 4 Susceptibility of An. aquasalis to infection with P. vivax from Brazilian symptomatic and asymptomatic patients. Infectivity to An. aquasalis mosquitoes (a) and oocysts (mean) at the midgut (b) are shown for symptomatic and asymptomatic blood samples used in MFAs. The means were compared using the Mann-Whitney test $\left.{ }^{* * *} P<0.0001\right)$, and the error bars represent the standard error of the mean (SEM) 

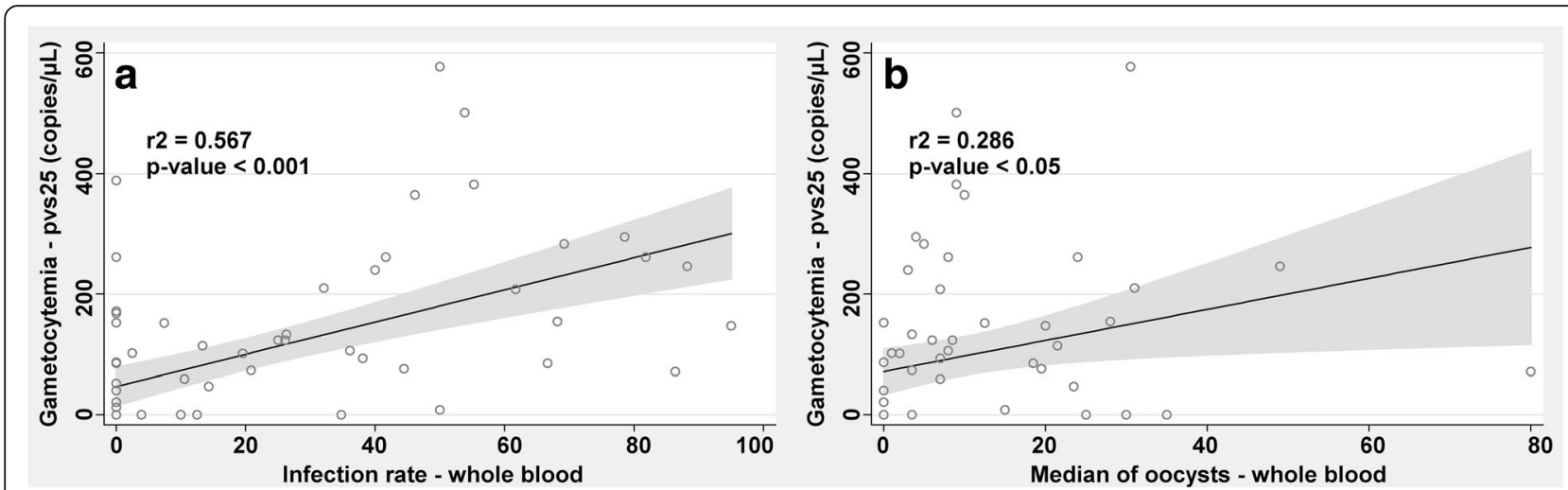

Fig. 5 Correlation between gametocytes and infection rate and oocysts median. The number of mature gametocytes (measured by pvs 25 expression) is shown for MFAs performed with whole blood depending on the infection rate (a) and median of oocysts (b). The values indicate the correlation coefficient $\left(r^{2}\right)(P<0.001$ and $P<0.05)$

of which $57 \%(8 / 14)$ were infective to $A n$. albimanus mosquitoes when blood was used in MFAs [39].

A report from the Brazilian Amazon has shown that $P$. vivax can infect some mosquito species at higher rates with increasing number of gametocytes $[A n$. darlingi $(Z=$ -2.9, $P<0.01)$ and An. aquasalis $(Z=-4.66, P<0.001)]$ [37]. A report from Peru showed an increase in the number of gametocytes about the percentage of infected mosquitoes $(P=0.001)$; the number of oocysts also increased $(P=0.09)$ [19]. In a recent study with $A n$. dirus in western Thailand a positive correlation was also found between the infection rate and gametocyte density $(P=$ $0.003)$ or pvs25 transcript abundance $\left(P=5 \times 10^{-6}\right)$. The mean oocyst density generally increased with blood parasite density $\left(P=2 \times 10^{-4}\right)$, gametocyte density $\left(P=4 \times 10^{-4}\right)$, and pvs25 transcript abundance $\left(P=1 \times 10^{-8}\right)$ [31]. The odds of $P$. vivax transmission for samples with gametocytes were significantly higher than those with no gametocytes based on smear examination (OR: 6.35, 95\% CI: 1.70-23.8, $P=0.003)$ [19].

The infection rate in this study was $41 \%$ for $A n$. aquasalis when using blood from $P$. vivax symptomatic patients. In fact, the infection rate has been shown to be variable depending on the study area and Plasmodium species. In Manaus, Amazon, $A n$. albitarsis (s.l.), An. aquasalis, An. darlingi, An. nuneztovari (s.l.) and An. triannulatus (s.l.), respectively, showed infection rates of $44.8 \%, 44.7 \%, 18.3 \%$, $24.5 \%$ and $8.8 \%$ [37]. In western Thailand between 2014 and 2015, 84\% (59/70) of symptomatic P. vivax blood samples were infective, i.e. at least one mosquito became infected with oocysts, and nearly 50\% of all $4389 A n$. dirus mosquitoes became infected [31]. In Peru, the infection rate was $94 \%$ for $A n$. darlingi/P. vivax [19].

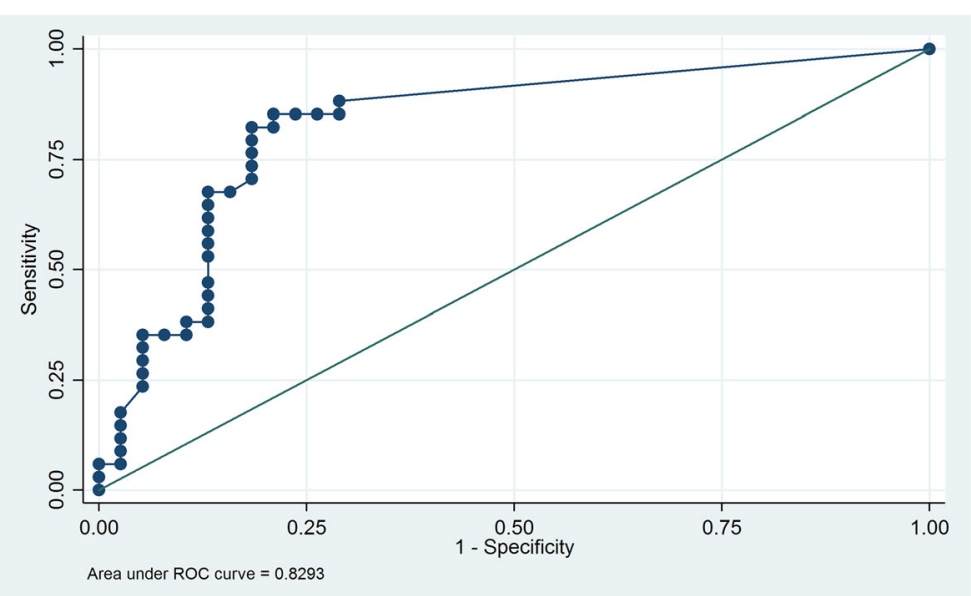

Fig. 6 The ROC curve demonstrated through the sensitivity and specificity of Anopheles aquasalis to P. vivax infection. ROC curve of gametocytemia of the symptomatic and asymptomatic individuals as a predictor for mosquitoes infections; AUROC $=0.8293$. The cut-off of 58.8 gametocytes/ $\mu$ l correctly classified $81.49 \%$ of mosquito infections 


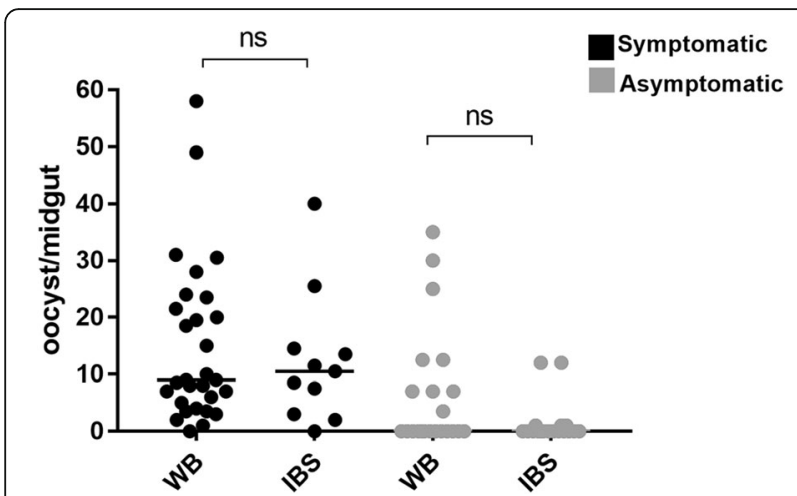

Fig. 7 Susceptibility of An. aquasalis to infection with P. vivax from whole blood or inactivated blood serum. The number of oocysts per midgut of infected An aquasalis is shown in black for symptomatic and grey for asymptomatic individuals. The source of $P$. vivax parasites was either whole blood (WB) or inactivated blood serum (IBS). The medians were compared using the Mann-Whitney test (ns, not significant)

Anopheles darlingi and An. aquasalis are the most important malaria vectors in Brazil; previous studies have shown differences in infection rates for these species [35]. We observed a high production of oocysts by symptomatic patients compared to those produced by asymptomatic patients (Fig. 4b). An. darlingi, An. albitarsis (s.l.), An. nuneztovari (s.l.) and An. triannulatus (s.l.) field populations, and the laboratory-colonised $A n$. aquasalis were shown to be susceptible to $P$. vivax under laboratory conditions with much higher infection rates than those reported in nature [37]. However, some studies have shown that mosquitoes infected in nature have few oocysts [40]. On average carriers of gametocytes at submicroscopic densities infected significantly fewer mosquitoes that in turn led to lower oocyst burdens [41-43].

Asymptomatic infections showing a higher gametocyte density (transcripts/ $\mu \mathrm{l}$ ) were as effective as symptomatic ones infecting mosquitoes. The ability to detect low levels of parasitemia is crucial to identifying asymptomatic carriers. Microscopy detected only 10 (40\%), asymptomatic infections compared to the PCR-based method that was positive for all 25 samples. This increased sensitivity of molecular methods makes them suitable for identification of asymptomatic malaria [30, 42-44].

Symptomatic patients are promptly treated and remain infectious to mosquitoes only for a few days. Since asymptomatic patients not recognised become the main potentially infectious source for long periods, this can at least partially compensate for the low infectivity rate [43]. Thus, studying its role in transmission should be crucial for understanding infection [44].

Individuals who have had several previous episodes of symptomatic malaria are more likely to become asymptomatic carriers upon Plasmodium infection [45]. A higher number of previous cases of malaria were reported in asymptomatic patients in this study (Table 1), underscoring the importance of immunity in this population. Inactivation of the blood serum before mosquito feeding resulted in higher infection rates in An. darlingi and An. triannulatus, but not in An. albitarsis (s.l.) and $A n$. aquasalis [37]. In the agreement, increased $A n$. aquasalis mosquito infectivity was not observed in this study when using an inactive serum (Fig. 7). Therefore, the immune response underlying asymptomatic infection still needs to be elucidated.

\section{Conclusion}

This study identified the potential of asymptomatic infection to contribute significantly to malaria transmission in the three communities studied in the city of Manaus. Individuals with submicroscopic parasitemias often do not present to health centres and become parasite reservoirs that go unnoticed by health surveillance and contribute to the endemicity of the disease in the Amazon region. Therefore, more studies are needed for this asymptomatic population to inform appropriate strategies as part of malaria control programs.

\section{Additional files}

Additional file 1: Table S1. PCR setup of Plasmodium-specific $\mathrm{qPCR}$ (QMAL) and P. vivax specific qPCR based on detection of 185 rRNA genes and RT-qPCR detecting pvs 25 transcripts. For sequences of primers and probes see $[35,38]$. (DOC $31 \mathrm{~kb})$

Additional file 2: Table S2. PCR cycling conditions used to detect parasites and gametocytes of Plasmodium vivax parasites. (DOC 32 kb)

Additional file 3: Table S3. Data from each membrane feeding assay of Anopheles aquasalis performed with samples from symptomatic and asymptomatic individuals of Plasmodium vivax. (DOC $151 \mathrm{~kb}$ )

Additional file 4: Table S4. Plasmids dilutions containing the sequence of the respective PCR product were used both as assay standards and to determine the limit of detection (LoD) of each assay. Generation of the plasmids is described in [35, 38]. (DOC $29 \mathrm{~kb}$ )

\section{Abbreviations}

AUROC: Area under the ROC curve; $C_{q}$ : Cycle threshold; IBS: Inactivated blood serum; MFA: Membrane feeding assays; qPCR: Quantitative polymerase chain reaction; ROC: Receiver operating characteristic; RTqPCR: Reverse transcription quantitative polymerase chain reaction; WB: Whole blood

\section{Acknowledgements}

We thank all the microscopists who made and read slides for this project: Wellington Silva, Maria Raimunda da Costa, Eckner Falcão, Marta Oliveira and Rosangela Melo in particular to the manager of Entomology and Malaria, Nelson Fé and Monica Costa, respectively of the Fundação de Medicina Tropical - Dr Heitor Vieira Dourado.

\section{Funding}

This research was financially supported by Bill and Melinda Gates Foundation, Coordenação de Aperfeiçoamento de Pessoal de Nível Superior (CAPES) and Fundação de Amparo à Pesquisa do Estado do Amazonas (FAPEAM).

\section{Availability of data and materials}

The datasets supporting the conclusions of this article are included within the article and its additional files. 


\section{Authors' contributions}

KMMC, AK and AA participated in data collection, laboratory procedures, and fieldwork. KMMC, CMRV and JBPL participated in the creation and donation of Anopheles to initiate the Anopheles aquasalis colony. ICR and SGMS helped in some experiments. KMMC, AK, AA, APMD, VSS, PFPP, QB, IM, ML, WMM and MGVBG participated in the general design of the study. KMMC, APMD, WMM and MGVBG were involved in interpreting data and preparing the manuscript. All authors read and approved the final manuscript.

\section{Ethics approval and consent to participate}

This study was approved by the Ethics Committee Human Research of the FMT-HVD (approval No. 51536/2012) and National Research Ethics Commission (CONEP approval No. 349 211/2013). All volunteers were instructed about the study objectives, and then they signed the informed consent forms. Patients diagnosed with malaria by thin blood smear were treated according to the guidelines of the Brazilian Ministry of Health [46]

\section{Consent for publication}

Not applicable.

\section{Competing interests}

The authors declare that they have no competing interests.

\section{Publisher's Note}

Springer Nature remains neutral with regard to jurisdictional claims in published maps and institutional affiliations.

\section{Author details}

1Programa de Pós Graduação em Medicina Tropical, Escola Superior de Ciências da Saúde, Universidade do Estado do Amazonas, Manaus, Brazil. ${ }^{2}$ Departamento de Ensino e Pesquisa, Fundação de Medicina Tropical Dr. Heitor Vieira Dourado, Manaus, Brazil. ${ }^{3}$ ISGlobal, Barcelona Centre for International Health Research (CRESIB), Hospital Clínic-Universitat de Barcelona, Barcelona, Spain. ${ }^{4}$ Fundação de Vigilância em Saúde, Manaus, Amazonas, Brazil. ${ }^{5}$ Instituto de Pesquisas Leônidas \& Maria Deane, Fiocruz, Manaus, Brazil. ${ }^{6}$ Instituto Oswaldo Cruz, Fiocruz, Rio de Janeiro, Brazil. ${ }^{7}$ Centro de Pesquisas René Rachou, Fiocruz, Belo Horizonte, Brazil. ${ }^{8}$ Walter and Eliza Hall Institute, Parkville, Australia.

Received: 19 September 2017 Accepted: 26 February 2018

Published online: 04 May 2018

\section{References}

1. World Health Organization. Global Health Observatory (GHO) data. 2015. http://www.who.int/gho/malaria/en/. Accessed 12 Dec 2016.

2. Sistema de Informação de Vigilância Epidemiológica - Notificação de casos. Brasil. Resumo Epidemiológico - Malaria 2016. http://200.214.130.44/sivep_ malaria/relatorio/rel_resumo_nacional_mensal.asp?tx_opcao_agravo= MALARIA\&opcao_agravo=B54\&dt_inicial=01/01/2016\&dt_final=30/11/ 2016\&niv_relatorio=NACIONAL. Accessed 12 Dec 2016.

3. Sistema de Informação de Vigilância Epidemiológica - Notificação de casos. Estado do Amazonas. Resumo Epidemiológico - Malaria 2016. http://200. 214.130.44/sivep_malaria/relatorio/rel_resumo_estado_mensal.asp?cd_uf_ relatorio $=3 \&$ tx_uf_relatorio $=$ AM\&tx_opcao_agravo=MALARIA\&opcao_ agravo=B54\&dt_inicial=01/01/2016\&dt_final=30/11/2016\&niv_relatorio= ESTADO. Accessed 12 Dec 2016.

4. Sistema de Informação de Vigilância Epidemiológica - Notificação de casos. Cidade de Manaus. Resumo Epidemiológico - Malaria 2016. http://200.214. 130.44/sivep_malaria/relatorio/rel_resumo_municipio_mensal.asp?cd_uf_ relatorio $=3 \&$ cd_municipio_relatorio $=161 \&$ tx_uf_relatorio $=A M \& t x \_$ municipio_relatorio=MANAUS\&tx_opcao_agravo=MALARIA\&opcao_agravo= B54 \&dt_inicial=01/01/2016\&dt_final=30/11/2016. Accessed 12 Dec 2016.

5. da Silva-Nunes M, Moreno M, Conn JE, Gamboa D, Abeles S, Vinetz JM, et al. Amazonian malaria: asymptomatic human reservoirs, diagnostic challenges, environmentally driven changes in mosquito vector populations, and the mandate for sustainable control strategies. Acta Trop. 2012;121:281-91.

6. Van Pelt-Koops JC, Pett HE, Graumans W, Van Der Vegte-Bolmer M, Van Gemert GJ, Rottmann M, et al. The spiroindolone drug candidate NITD609 potently inhibits gametocytogenesis and blocks Plasmodium falciparum transmission to Anopheles mosquito vector. Antimicrob. Agents Chemother. 2012;56:3544-3548.
7. Miura K, Keister DB, Muratova OV, Sattabongkot J, Long CA, Saul A. Transmission-blocking activity induced by malaria vaccine candidates pfs 25/pvs25 is a direct and predictable function of antibody titer. Malar. J. 2007; 6:107.

8. Tachibana M, Suwanabun N, Kaneko O, Iriko H, Otsuki H, Sattabongkot J, et al. Plasmodium vivax gametocyte proteins, pvs48/45 and pvs47, induce transmission-reducing antibodies by DNA immunization. Vaccine. 2015;33: 1901-8.

9. Arévalo-Herrera M, Vallejo AF, Rubiano K, Solarte Y, Marin C, Castellanos A, et al. Recombinant pvs48/45 antigen expressed in $E$. coli generates antibodies that block malaria transmission in Anopheles albimanus mosquitoes. PLoS One. 2015;10:e0119335.

10. Abdel-Wahab A, Abdel-Muhsin A-MA, Ali E, Suleiman S, Ahmed S, Walliker $D$, et al. Dynamics of gametocytes among Plasmodium falciparum clones in natural infections in an area of highly seasonal transmission. J Infect Dis. 2002;185:1838-42.

11. Babiker HA, Schneider P. Application of molecular methods for monitoring transmission stages of malaria parasites. Biomed Mater. 2008;3:34007.

12. Babiker HA, Schneider P, Reece SE. Gametocytes: insights gained during a decade of molecular monitoring. Trends Parasitol. 2008:525-30.

13. Beurskens $M$, Mens $P$, Schallig $H$, Syafruddin D, Asih PBS, Hermsen $R$, et al. Quantitative determination of Plasmodium vivax gametocytes by real-time quantitative nucleic acid sequence-based amplification in clinical samples. Am J Trop Med Hyg. 2009;81:366-9.

14. Sattabongkot J, Maneechai N, Rosenberg R. Plasmodium vivax: gametocyte infectivity of naturally infected Thai adults. Parasitology. 1991;102(Pt 1):27-31.

15. Mulder B, Lensen T, Tchuinkam T, Roeffen W, Verhave JP, Boudin C, et al. Plasmodium falciparum: membrane feeding assays and competition ELISAs for the measurement of transmission reduction in sera from Cameroon. Exp Parasitol. 1999;92:81-6.

16. van der Kolk M, De Vlas SJ, Saul a v d V-BM, Eling WM, Sauerwein RW. Evaluation of the standard membrane feeding assay (SMFA) for the determination of malaria transmission-reducing activity using empirical data. Parasitology. 2005;130:13-22.

17. Sattabongkot J, Maneechai N, Phunkitchar V, Eikarat N, Khuntirat B, Sirichaisinthop J, et al. Comparison of artificial membrane feeding with direct skin to estimate the infectiousness of Plasmodium vivax gametocyte carriers to mosquitoes. Am J Trop Med Hyg. 2003;69:529-35.

18. Bousema T, Drakeley C. Epidemiology and infectivity of Plasmodium falciparum and Plasmodium vivax gametocytes in relation to malaria control and elimination. Clin Microbiol Rev. 2011;24:377-410.

19. Bharti AR, Chuquiyauri R, Brouwer KC, Stancil J, Lin J, Llanos-Cuentas A, Vinetz JM. Experimental infection of the neotropical malaria vector Anopheles darlingi by human patient-derived Plasmodium vivax in the Peruvian Amazon. Am J Trop Med Hyg. 2006;75:610-6.

20. Riley EM, Bennett S, Jepson A, Hassan-King M, Whittle H, Olerup O, et al. Human antibody responses to pfs230, a sexual stage-specific surface antigen of Plasmodium falciparum: non-responsiveness is a stable phenotype but does not appear to be genetically regulated. Parasite Immunol. 1994;16:55-62.

21. Roeffen W, Geeraedts F, Eling W, Beckers P, Kumar N, Lensen T, Sauerwein R. Transmission blockade of Plasmodium falciparum malaria by anti-pfs230 specific antibodies is isotype dependent. Infect Immun. 1995;63:467-71.

22. Healer J, McGuinness D, Hopcroft P, Haley S, Carter R, Riley E. Complementmediated lysis of Plasmodium falciparum gametes by malaria-immune human sera is associated with antibodies to the gamete surface antigen pfs230. Infect Immun. 1997;65:3017-23.

23. Lensen AH, Bolmer-Van de Vegte M, van Gemert GJ, Eling WM, Sauerwein RW. Leukocytes in a Plasmodium falciparum-infected blood meal reduce transmission of malaria to Anopheles mosquitoes. Infect Immun. 1997;65:3834-7.

24. Sinden RE, Smalley ME. Gametocytes of Plasmodium falciparum phagocytosis by leucocytes in vivo and in vitro. Trans R Soc Trop Med Hyg. 1976;70:344-5.

25. Naotunne TS, Karunaweera ND, Mendis KN, Carter R. Cytokine-mediated inactivation of malarial gametocytes is dependent on the presence of white blood cells and involves reactive nitrogen intermediates. Immunology. 1993; 78:555-62.

26. Ponnudurai T, van Gemert GJ, Bensink T, Lensen AHW, Meuwissen JHET. Transmission blockade of Plasmodium falciparum: its variability with 
gametocyte numbers and concentration of antibody. Trans R Soc Trop Med Hyg. 1987;81(3):491.

27. Zoghi S, Mehrizi A, Raeisi A, Haghdoost A, Turki H, Safari R, et al. Survey for asymptomatic malaria cases in low transmission settings of Iran under elimination programme. Malar. J. 2012;11:126.

28. Baum E, Sattabongkot J, Sirichaisinthop J, Kiattibutr K, Jain A, Taghavian O, et al. Common asymptomatic and submicroscopic malaria infections in western Thailand revealed in longitudinal molecular and serological studies: a challenge to malaria elimination. Malar J. 2016;15:333.

29. Laishram DD, Sutton PL, Nanda N, Sharma VL, Sobti RC, Carlton JM, et al. The complexities of malaria disease manifestations with a focus on asymptomatic malaria. Malar J. 2012;11:29.

30. Alves FP, Durlacher RR, Menezes MJ, Krieger H, da Silva LHP, Camargo EP. High prevalence of asymptomatic Plasmodium vivax and Plasmodium falciparum infections in native Amazonian populations. Am J Trop Med Hyg. 2002;66:641-8

31. Kiattibutr K, Roobsoong W, Sriwichai P, Saeseu T, Rachaphaew N, Suansomjit C, et al. Infectivity of symptomatic and asymptomatic Plasmodium vivax infections to a Southeast Asian vector, Anopheles dirus. Int J Parasitol. 2017; 47:163-70.

32. Starzengruber $P$, Fuehrer HP, Ley B, Thriemer K, Swoboda P, Habler VE, et al. High prevalence of asymptomatic malaria in south-eastern Bangladesh. Malar J. 2014;13:16.

33. Bousema T, Okell L, Felger I, Drakeley C. Asymptomatic malaria infections: detectability, transmissibility and public health relevance. Nat Rev Microbiol. 2014;12:833-40.

34. Howes RE, Battle KE, Mendis KN, Smith DL, Cibulskis RE, Baird JK, Hay SI. Global epidemiology of Plasmodium vivax. Am J Trop Med Hyg. 2016:16-0141.

35. Wampfler R, Mwingira F, Javati S, Robinson L, Betuela I, Siba P, et al. Strategies for detection of Plasmodium species gametocytes. PLoS One. 2013:8:e76316.

36. Orfano AS, Duarte APM, Molina-Cruz A, Pimenta PF, Barillas-Mury C, Mitchell C. Plasmodium yoelii nigeriensis (N67) is a robust animal model to study malaria transmission by South American Anopheline mosquitoes. PLoS One. 2016;11:e0167178

37. Rios-Velásquez CM, Martins-Campos KM, Simões RC, Izzo T, dos Santos EV, Pessoa F a C, et al. Experimental Plasmodium vivax infection of key Anopheles species from the Brazilian Amazon. Malar J. 2013;12:460.

38. Rosanas-Urgell A, Mueller D, Betuela I, Barnadas C, Iga J, Zimmerman PA, et al. Comparison of diagnostic methods for the detection and quantification of the four sympatric Plasmodium species in field samples from Papua New Guinea. Malar J. 2010;9:361.

39. Vallejo AF, Garcia J, Amado-Garavito AB, Arevalo-Herrera M, Herrera S. Plasmodium vivax gametocyte infectivity in sub-microscopic infections. Malar J. 2016:15:48.

40. Da Silva ANM, Santos CCB, Lacerda RN, Machado RLD, Póvoa MM. Susceptibility of Anopheles aquasalis and An. darlingi to Plasmodium vivax VK210 and VK247. Mem Inst Oswaldo Cruz. 2006;101:547-50.

41. Adak T, Singh OP, Das MK, Wattal S, Nanda N. Comparative susceptibility of three important malaria vectors Anopheles stephensi, Anopheles fluviatilis, and Anopheles sundaicus to Plasmodium vivax. J Parasitol. 2005;91:79-82.

42. Baum E, Sattabongkot J, Sirichaisinthop J, Kiattibutr K, Davies DH, Jain A, et al. Submicroscopic and asymptomatic Plasmodium falciparum and Plasmodium vivax infections are common in western Thailand - molecular and serological evidence. Malar J. 2015;14:95.

43. Alves FP, Gil LHS, Marrelli MT, Ribolla PEM, Camargo EP, Da Silva LHP. Asymptomatic carriers of Plasmodium spp. as infection source for malaria vector mosquitoes in the Brazilian Amazon. J Med Entomol. 2005:42:777-9.

44. Lin JT, Saunders DL, Meshnick SR. The role of submicroscopic parasitemia in malaria transmission: what is the evidence? Trends Parasitol. 2014:183-90.

45. Andrade BB, Rocha BC, Reis-Filho A, Camargo LMA, Tadei WP, Moreira LA, et al. Anti-Anopheles darlingi saliva antibodies as marker of Plasmodium vivax infection and clinical immunity in the Brazilian Amazon. Malar J. 2009;8:121.

46. Ministério da Saúde, Saúde $S$ de V em. Manual do Diagnóstico Laboratorial de Malária. Segunda. Brasília; 2009.

\section{Submit your next manuscript to BioMed Central and we will help you at every step:}

- We accept pre-submission inquiries

- Our selector tool helps you to find the most relevant journal

- We provide round the clock customer support

- Convenient online submission

- Thorough peer review

- Inclusion in PubMed and all major indexing services

- Maximum visibility for your research

Submit your manuscript at www.biomedcentral.com/submit 